\title{
Modifications to Standard Forms of Contract: the Impact on Readability
}

Raufdeen Rameezdeen, (University of South Australia, Australia)

Anushi Rodrigo, (University of Northumbria, UK)

\begin{abstract}
Lack of clarity in contract documents can lead to disputes between contracting parties. Standard form contracts have evolved due to construction business becoming increasingly complex and the difficulty in drafting bespoke conditions of contract for each project. Numerous advantages have been identified in using standard forms of contract. However, clients often modify some clauses in order to include specific requirements for a project. While the consequences of ill-modifications to standard forms have been researched, no study has been done on the impact of these modifications on the clarity and readability of the document. Using 281 modified clauses from large infrastructure projects implemented in Sri Lanka, this study found that on balance modifications generally make the document more difficult to read; $60 \%$ of the sample clauses were more difficult to read compared to $40 \%$ becoming easier. More than $50 \%$ of the original and modified clauses were still at the 'very difficult' level of readability, which requires the equivalent of post-graduate level to understand. The study contends that modifications have not resulted in improved readability. The study highlights the necessity of clear and plain language when modifying contract documents.
\end{abstract}

Keywords: Construction contract, FIDIC, Readability, Standard form, Infrastructure

\section{Introduction}

A large number of stakeholders work together to deliver a construction project. Unhindered communication among these parties is essential for a successful outcome. The rights and obligations of the contracting parties are communicated through the conditions of contract used in a construction project. This document plays a major role during the pre- and postcontract stages. Due to the difficulty in drafting bespoke conditions for each project, standard forms have evolved over the years. These standard form contracts have been developed by independent professional bodies or government organizations in order to provide uniformity and a level playing field for the parties tendering for a project. Clients often modify clauses in order to include their own requirements or project-specific conditions. Legal scholars warn that there may be unintended consequences of ill modifications made by mostly non-legal professionals. They recommend that modifications are only made in unavoidable circumstances.

Non-legal practitioners criticize standard form contracts for being difficult to read and understand. This claim is substantiated by the fact that the major users of these documents are contract administrators, project managers, quantity surveyors, architects and engineers who essentially do not come from a legal background. There is a plea for the use of plain language devoid of legalese and complex language structures in standard forms. New Engineering Contract (NEC, 2005) and ConsensusDOCS (2007) are a positive response to this request and are considered to be much easier to read and understand (Wright \& Ferguson, 2009). Modifications made to the clauses in a standard form might alter the readability level and lead to difficulty in understanding these clauses. Studies have shown that lack of clarity in contract documents can lead to misunderstanding between parties and even disputes (Cheung \& Yiu, 2007; Harmon, 2003). According to Barnes (2007) inability to comprehend a contract term cannot be used as a defence according to the "duty-to-read 
doctrine" of contract law. Based on this doctrine, parties are assumed to be well versed with all the terms in a contract they sign (Pettit, 2012). Thus, the onus is on the signatory to comprehend the contents of a contract before a contract is signed (Bell, 2009).

While past studies have shown the technical and legal consequences of modifications to standard form contracts, no study has yet been published on the impact of language structure and clarity. It is important to understand how the modifications will affect the clarity of standard forms and their interpretation. This study examined the language structure of modifications to standard form contracts in order to understand the impact on clarity and readability of the modified document. The study is expected to shed some light on the necessity of clear and plain language for contract documents. The paper continues with a literature review on standard form contracts followed by research method, results, discussion and conclusions.

\section{Literature Review}

Good communication among parties can help ensure that a project functions smoothly. The contract document is the main vehicle through which a pre-contract business deal is conveyed through to the implementation stage of a project. It communicates the project's legal, financial and technical framework to its post-contract users (Bubshait \& Almohawis, 1994). It becomes a working document on which the entire project management relies. Thus, clarity of the contract document is critical for making the parties understand their rights and obligations as well as the rules applicable to the functioning of the project. Conditions of contract are often criticized for being difficult to read and understand. Long sentences, poor layout and presence of legalese are considered to be the main causes of lack of clarity (Bunni, 2003; Chong \& Zin, 2010). The major issue is the difficulty of use of this document by non-legal professionals, who are in fact the main users (Ali \& Wilkinson, 2010). Lack of clarity is often justified as a compromise to achieve legal precision (Thomas et al., 1994). As legal professionals are typically not employed on day-to-day contract administration of a construction project, there has been a plea to make this document readable (Ali \& Wilkinson, 2010).

The complexity of construction business necessitates the use of lengthy and carefully written standard form contracts developed by independent professional bodies (Pettit, 2012; Hughes \& Shinoda, 1999; Bubshait \& Almohawis, 1994; Sweet, 1989). Advantages of standard form contract have been highlighted by many researchers (Pettit, 2012; Shnookal \& Charrett, 2010; Bell, 2009; Barnes, 2007; Bunny, 2005; Seifert, 2005; Hughes \& Greenwood, 1996; Perry, 1995; Sweet, 1989). These are summarised below:

1. It can be used for various types of projects and client requirements.

2. It embodies industry practices and customs.

3. Parties can be comfortable with the fact that it has been tried and tested over a long period of time.

4. Fair allocation of risks between parties.

5. In a competitive tendering environment, it provides a uniform basis for pricing without the fear of hidden costs.

6. The tendered price is likely to be lower as contractors do not have to price additional risks associated with interpretation of bespoke contracts or clauses.

7. Transaction cost involved in negotiating a contract is reduced.

8. It looks at three dimensions together, namely: the wider legal context through statutes and case law, other documents forming the contract, and areas of possible disagreements between parties.

9. The familiarity with clauses improves communication and efficiency of contract administration between client, contractor and the contract administrator. 
However, some researchers have identified limitations of standard form contracts. According to Barnes (2007) they are usable across a broad spectrum of applications, but are seldom entirely appropriate for a particular circumstance. As a consequence, standard form contracts are often modified by the client. Shnookal and Charrett (2010) observe that the number of modifications made to standard forms have increased over the last twenty years in Australia. According to Bell (2009) the majority of contracts used in Australia today are heavily modified standard forms to reflect the applicable delivery method or risk profile. The major reasons for modifications are the client's general dissatisfaction with risk allocation in standard forms and numerous new project delivery systems that demand changes to many clauses (Shnookal \& Charrett, 2010). According to Chen et al. (2013) standard forms are very often modified in favour of the client.

There is a danger in modification as it can lead to unintended problems and can put the parties in a much worse situation (Pettit, 2012). Using a case study in Vietnam, Chen et al. (2013) show the wide range of problems encountered when FIDIC Standard Form of EPC/Turnkey is modified to accommodate client requirements. Specifically, the modifications change the balance in risk allocation and force the contractor to shoulder the majority of risks (Chen et al., 2013). Many construction disputes in Australia have started due to inconsistencies between modifications and the rest of the contract document (Shnookal \& Charrett, 2010). According to Sweet (1989) modifications to a standard form contract need more technical skills than what the average lawyer has. Koksal (2011) is of the view that modifications to standard form should be implemented only for inclusion of project-specific attributes and should not be used for re-allocation of risk.

While modifications are inevitable due to numerous project-specific attributes having to be incorporated, the resultant document should be as good as the original standard form (Pettit, 2012). While technical and legal consequences of modifications are easy to deal with, the impact on clarity and readability are very difficult to control by the contract drafters. The drafters' main aim would be to ensure that there is no ambiguity whatsoever, rather than considering how easy it is to read the modifications. Interestingly, literature is silent on the impact of modifications on clarity and readability. No systematic study has been reported on the consequences of modifications on clarity and readability. Therefore, the present study is considered to be useful in filling this particular gap in the literature.

\section{Research Method}

Clarity of a document may be assessed using many different techniques and readability formulae are the most commonly used. Readability has been defined as the ease of understanding or comprehension due to the style of writing' (DuBay, 2004, p.3). DuBay (2004) identified four basic elements, which decide the ease of reading of a text. These are illustrated in Figure 1.

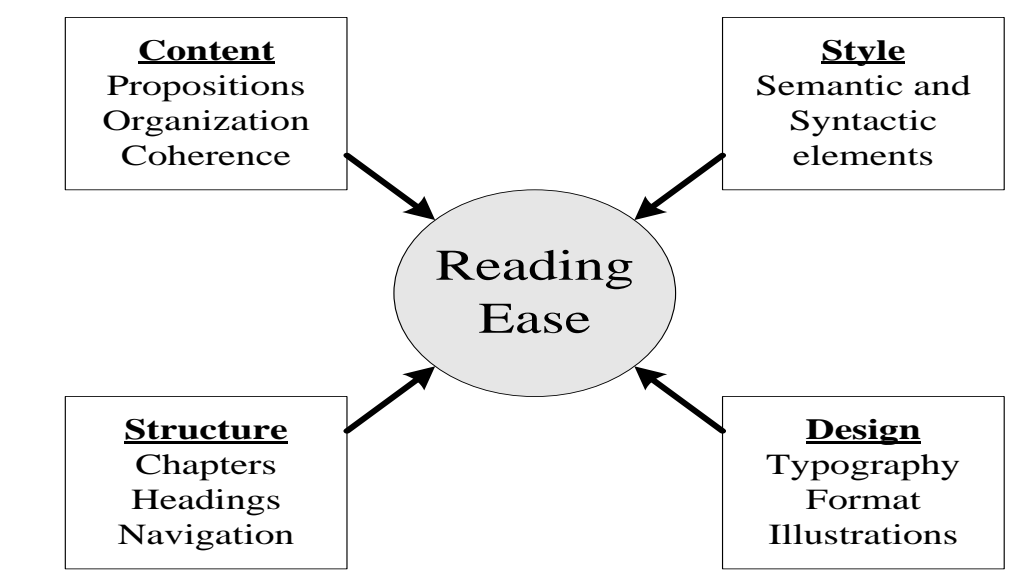

Figure 1 Basic elements of readability (Source: Dubay, 2004, p.18) 
Literature shows that readability formulae are the most popular tools for assessing the clarity of a text. Readability formulae are based on sentence structure and complexity (Koo et al., 2003; Hall 2006). Although many readability formulae are available, Flesch Reading Ease Score (FRES) is a popular, tested and reliable tool for readability testing (Rameezdeen \& Rajapakse, 2007). FRES is consistent and highly associated with other indices (Paz et al. 2009). Therefore, FRES is considered to be suitable for assessing the readability levels of modified clauses against the standard conditions in this research. It is obtained using the following formula:

$$
\mathrm{FRES}=206.835-(1.015 \times \mathrm{ASL})-(84.6 \times \mathrm{ASW}) \quad \text { Equation }(1)
$$

Where,

ASL = Average sentence length (the number of words divided by the number of sentences) ASW = Average number of syllables per word (the number of syllables divided by the number of words).

The data for this research came from twelve large infrastructure projects implemented in Sri Lanka that used FIDIC standard forms; both FIDIC Conditions of Contract for Works of Civil Engineering 4th edition (1987) popularly known as the Red Book; and the FIDIC Conditions of Contract for Building and Engineering Work Designed by Employer (1999) and called the New Red Book (FIDIC, 1987; FIDIC 1999). Contract documents were sourced from project implementing agencies. Altogether 281 modified contract clauses were extracted from the contract conditions of these projects to be used as the sample. These modified clauses along with their original counterparts became the unit of analysis of the research. The modified and original clauses were subjected to the readability test based on equation 1 electronically. In order to verify consistency of the results, about 25 randomly selected clauses (approximately $10 \%$ of the sample) were re-analysed by a second person manually (in this case the co-author of this paper).

While readability formulae are a popular means of establishing the clarity and readability of a text, researchers highlight the following limitations:

1. They do not consider meanings of words or sentences (Harrison \& Bakker, 1998).

2. They evaluate only the text that could be quantified (Orlow et al., 2003).

3. They do not take word order or grammar into consideration (Rutherford, 2003)

4. They do not consider reader characteristics (Courtis, 1998).

Despite these drawbacks, readability formulae still offer valuable predictions on clarity of a text (Velez \& Ashworth, 2007). As it is an objective and reliable tool, practitioners and researchers prefer these formulae over other much more sophisticated yet subjective tools. They are very simple and easy to use and helpful in detecting certain obvious errors such as excessive sentence length (Sydserff \& Weetman, 2002).

\section{Results}

The FRES values of the 281 modified clauses and their original versions provide a snapshot of what happens when modifications were implemented to the standard form contract. FRES ranges from $0-100$, where a score of 0 indicates a text that is very difficult to read, while a score of 100 is very easy to read. Table 1 provides a guide to FRES using an example of the difficulty level based on different reading grades. As shown in Figure 2 the median FRES value of modified clauses is slightly lower than its original versions, indicating that modifications have made the clauses slightly more difficult to read. Both the modified and original clauses are in the 'very difficult' band indicating a post-graduate level of readability.

The distribution of FRES values of the original clauses and after modifications is given in Table 2. It shows the effect of modifications on readability levels. Modifications have 
increased the difficulty of reading by a small proportion. The percentage of 'very difficult' clauses has increased from $57 \%$ to $62 \%$. Some of the 'difficult' and 'fairly difficult' clauses have become 'very difficult'. Additionally, modifications have made some of the 'very easy' and 'fairly easy' clauses 'standard'.

\begin{tabular}{|c|c|c|}
\hline FRES & Difficulty level & Estimated reading grade \\
\hline $0-30$ & Very difficult & Postgraduate \\
\hline $31-50$ & Difficult & College \\
\hline $51-60$ & Fairly difficult & High school \\
\hline $61-70$ & Standard & 8th to 9th Grade \\
\hline $71-80$ & Fairly easy & 7 th Grade \\
\hline $81-90$ & Easy & 5th to 6th Grade \\
\hline $91-100$ & Very easy & 3rd to 4th Grade \\
\hline
\end{tabular}

Table 1 FRES guide to comparisons of readability (Source: Rameezdeen \& Rajapakse 2007)

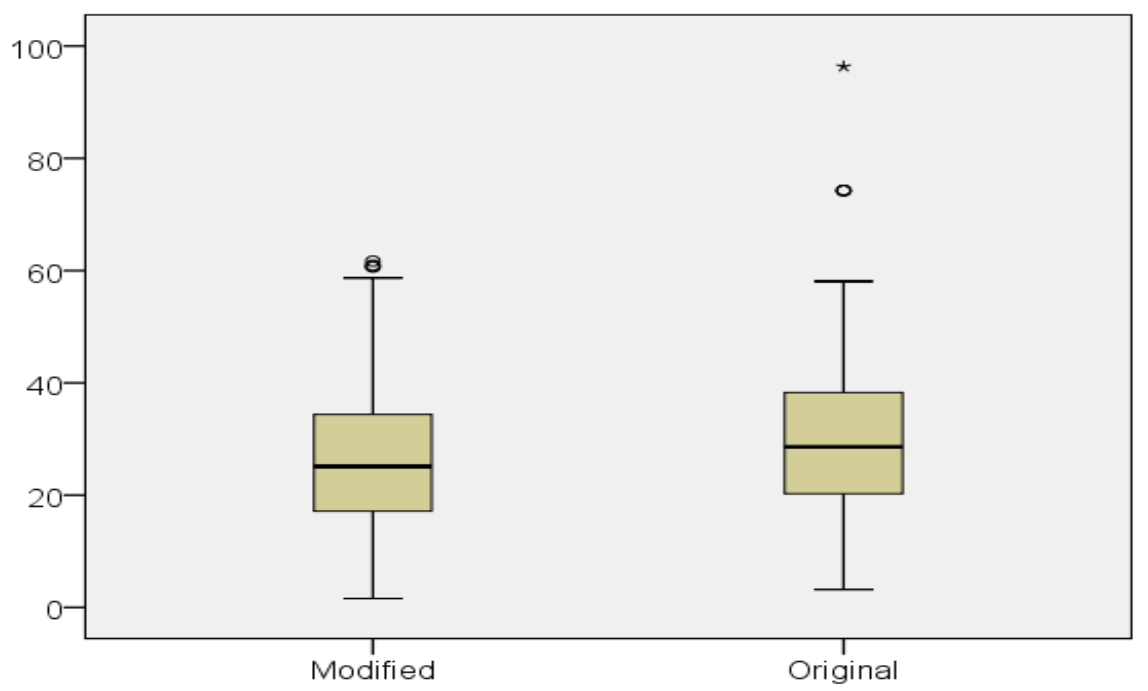

Figure 2 Box Plot showing the changes in FRES due to modifications $(n=281)$

\begin{tabular}{|c|c|c|c|}
\hline \multirow{2}{*}{ FRES } & Difficulty level & \multicolumn{2}{|c|}{ Percentage of clauses } \\
\cline { 3 - 4 } & & Original $(\mathbf{n = 2 8 1})$ & Modified $(\mathbf{n = 2 8 1})$ \\
\hline $0-30$ & Very difficult & 56.9 & 62.0 \\
\hline $31-50$ & Difficult & 40.2 & 32.8 \\
\hline $51-60$ & Fairly difficult & 1.1 & 3.9 \\
\hline $61-70$ & Standard & - & 1.3 \\
\hline $71-80$ & Fairly easy & 1.4 & 0 \\
\hline $81-90$ & Easy & - & 0 \\
\hline $91-100$ & Very easy & 0.4 & 0 \\
\hline Total & 100.0 & 100.0 & 100.00 \\
\hline
\end{tabular}

Table 2 Readability levels of original and post-modifications

Though Table 2 summarises the results at a glance, the magnitude of change in readability as a result of modifications is not apparent. Hence, the difference between FRES value of the original and modified clauses were looked at in detail. Using equation 2 , the percentage deviation of FRES value was obtained for each clause. The analysis shows that while readability levels of 167 clauses declined the remaining 114 improved (see Table 3). Most deviations were between $1-25 \%$ reductions in readability. On the extreme positive end, readability level of 16 clauses more than doubled due to the modification. While it is clear that about $60 \%$ of modifications have impacted negatively on readability, it is not clear 
whether they were originally easy to read or difficult to read clauses. The relationship between deviation and original FRES values could provide a better picture of which clauses have become more difficult or easier to read. Figure 3 illustrates this relationship and the general trend of the graph indicates that difficult to read clauses have become much easier to read while some of the easier to read clauses have become slightly more difficult. It shows that the improvements are much more pronounced than the deterioration and this is clearly the case for clauses that were originally very difficult.

Deviation $(\%)=\frac{\text { Modified FRES-Original FRES }}{\text { Original FRES }} \times 100 \quad$ Equation (2)

\begin{tabular}{|c|c|c|}
\hline Impact on readability & Deviation (based on equation 2) & Number of clauses \\
\hline \multirow[t]{5}{*}{ Increase } & $>100 \%$ & 16 \\
\hline & $76-100 \%$ & 4 \\
\hline & $51-75 \%$ & 17 \\
\hline & $26-50 \%$ & 19 \\
\hline & $1-25 \%$ & 58 \\
\hline \multirow[t]{5}{*}{ Decrease } & $1-25 \%$ & 99 \\
\hline & $26-50 \%$ & 42 \\
\hline & $51-75 \%$ & 21 \\
\hline & $76-100 \%$ & 4 \\
\hline & $>100 \%$ & 1 \\
\hline \multicolumn{2}{|r|}{ Total } & 281 \\
\hline
\end{tabular}

Table 3 Impact of modifications on readability

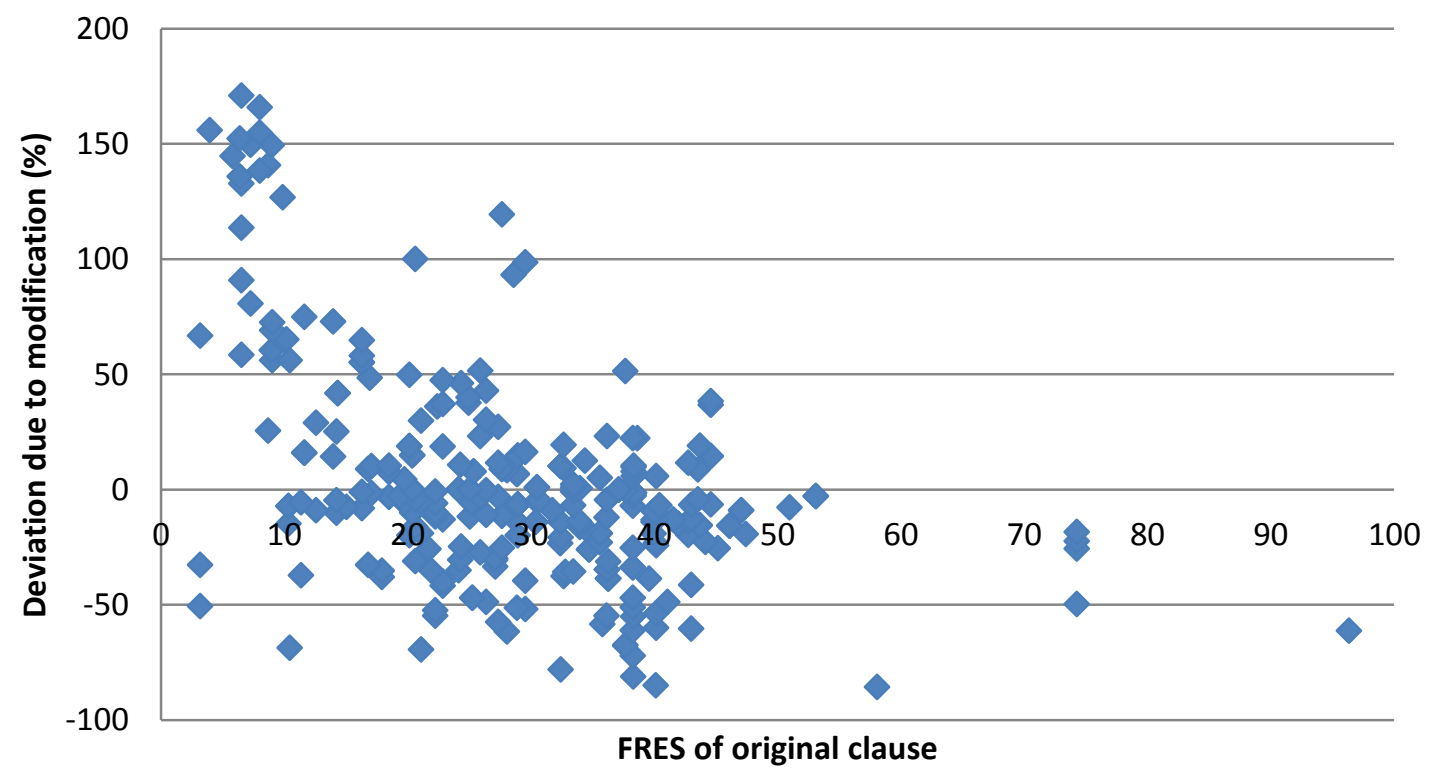

Figure 3 Relationship between original FRES and deviation $(n=281)$

\section{Discussion}

Using feedback from practitioners, standard form contracts have been updated regularly. For example, FIDIC revised its standard form five times since its first publication in 1957. Rameezdeen and Rodrigo (2013) showed that clarity has continually improved in each of these new editions. Lack of clarity in contract documents can adversely affect the relationship between the client and the contractor and can even lead to disputes. Often an ambiguous clause may be the focal point of a dispute. FIDIC is commonly used in Sri Lanka 
for very large-scale infrastructure projects funded by the government or donor agencies. These projects are designed and implemented by foreign consultants and contractors. According to Fawzy and El-adaway (2012), negative impacts of claims and disputes can be intensified under international projects due to the involvement of many multinational and multicultural stakeholders. A dispute in an infrastructure project could be very costly and affect the duration of a project. Given that often funding is tight, developing countries may find this difficult to absorb.

Preventing disputes should be an important goal of contract drafters involved in these projects. When they modify clauses, unintentional problems might creep into a project that could have a devastating impact on the project's success. While past research has looked into these unintended impacts of contract modifications, very little is known about their impact on readability and clarity of the document. While the results of this study show an average reduction of readability in the modified clauses, some of the very difficult to read clauses have become easier to read. Some of these incremental improvements are substantial. Despite the improvements to a few clauses, more than $50 \%$ of the original and modified clauses are still at the 'very difficult' level of readability, which equates to requiring post-graduate study level to understand. Studies by Rameezdeen and Rodrigo (2013), Ali and Wilkinson (2010), Raj et al. (2009) and Bunni (2003) show the majority of FIDIC contract conditions are very difficult to read. Modifications to contact conditions have not brought significant improvements on readability.

While these results are useful for Sri Lanka, it can also be relevant to other developing countries. FIDIC is an internationally used document. It is used by many developing countries for their infrastructure development programs. The general FIDIC standard form has been adopted by many development agencies and a special version is being formulated to be used in conjunction with international development projects. This special version called the 'Multilateral Development Bank' contract came into existence in 2005 and has been used by the African Development Bank, the Asian Development Bank, the Black Sea Trade and Development Bank, the Caribbean Development Bank, the European Bank for Reconstruction and Development, the Inter-American Development Bank, the World Bank, the Islamic Bank for Development, and the Nordic Development Fund (Swiney, 2007). As modifications to standard forms are inevitable in differing project settings, the resultant readability and clarity of the document need to be seriously considered. In a globalized construction industry, communication and understanding among stakeholders from different countries and cultural backgrounds calls for a very careful scrutiny during the modification process of the contract conditions. The study has a general message to contract drafters: When drafting modifications to contract conditions, consider how the readability and clarity can be improved. However, further research needs to be conducted covering not only readability but also other aspects of clarity.

\section{Conclusions}

The study analysed the impact of modifications to readability of standard form contracts using FIDIC 1987 and 1999 as the base documents. Using 281 modified clauses from large infrastructure projects implemented in Sri Lanka, the study found that these modifications in general make the document more difficult to read. $60 \%$ of the sample clauses became more difficult to read while $40 \%$ became easier. The majority of changes resulted in a $0-25 \%$ decline in FRES value. The general observation is that difficult to read clauses have become much easier to read while some of the easier to read clauses have become slightly more difficult. Overall, more than $50 \%$ of the original and modified clauses were still in the 'very difficult' level of readability requiring the equivalent of post-graduate level study to understand them. The study shows that modifications have not resulted in improved readability. 
Despite the valuable findings, the study suffers from some limitations. First, the research design itself has a few shortcomings as explained in the research method. Studies using readability formulae have these inherent weaknesses that could not be eliminated by the research design. While readability formulae provide an objective measurement of the level of difficulty of reading, it is essentially based on text that is quantifiable. Second, this study used a 'purposive sampling' method to obtain 281 modified clauses from large infrastructure projects implemented in Sri Lanka. While they are useful in explaining the association between the modifications and the change in readability, the fact that the sample is not random must be accepted as a limitation. Nevertheless, the study is useful as it is based on a very large sample that was obtained from infrastructure projects that used FIDIC standard forms.

\section{References}

Ali, N.A.N.A. and Wilkinson, S. (2010) 'Modernising construction contract drafting - a plea for good sense', Proceedings of the 18th CIB World Building Congress, 10-13 May, Salford, United Kingdom, 323-345.

Barnes, W.R. (2007) 'Toward a fairer model of consumer assent to standard form contracts: In defence of restatement subsection 211(3)', Washington Law Review, 82, 227-274.

Bell, M. (2009) 'Standard form construction contracts in Australia: Are our reinvented wheels carrying us forward?', Building and Construction Law Journal, 25 (2), 79-93.

Bubshait A.A. and Almohawis, S.A. (1994) 'Evaluating the general conditions of a construction contract', International Journal of Project Management, 12,133-136.

Bunni, N. G. (2005) The FIDIC form of contract, Third ed., Blackwell, Oxford.

Bunni, N. G. (2003) Risk and insurance in construction, Spon Press, London.

Chen C., Jiang C. and Li, H. (2013) 'Modifications to the FIDIC Silver book in a buyer's context: A case study of the Haiphong Power Plant II project', Applied Mechanics and Materials, 357, 2498-2504.

Cheung, S.O. and Yiu, T.W. (2007) 'Are construction disputes inevitable?', Building and Environment, 42, 752-761.

Chong, H. Y. and Zin, R.M. (2010) 'A case study into the language structure of construction standard form in Malaysia', International Journal of Project Management, 28, 255-261.

ConsensusDOCS (2007) ConsesnsusDOCS 200 - Agreement and general conditions between owner and constructor (lump sum), Arlington, VA.

Courtis, J.K. (1998) 'Annual report readability variability: tests of the obfuscation hypothesis', Accounting Auditing and Accountability Journal, 11, 459-471.

DuBay, W.H. (2004) The principles of readability, Impact Information, California.

Fawzy S.A. and El-adaway, I. (2012) 'Contract administration guidelines for U.S. contractors working under World Bank-funded projects', Journal of Legal Affairs and Dispute Resolution in Engineering and Construction, ASCE, 4 (2), 40-50.

FIDIC (1999) Conditions of Contract for Building and Engineering Works Designed by the Employer, first ed. Federation Internationale des ingeneurs-conseils, Geneva.

FIDIC (1987) Conditions of Contract for Works of Civil Engineering Construction, fourth ed. Federation Internationale des ingeneurs-conseils, Geneva.

Hall, J.C. (2006) 'The readability of original articles in surgical journals', ANZ Journal of Surgery, 76, 68-70.

Harmon, K.M.J. (2003) 'Resolution of construction disputes: a review of current methodologies', Leadership and Management in Engineering, 3, 187-201. 
Harrison, S. and Bakker, P. (1998) 'Two new readability predictions for the professional writer: pilot trials', Journal of Research in Reading, 21, 121-138.

Hughes, W. and Greenwood, D. (1996) 'The standardization of contracts for construction', International Construction Law Review, 13 (2), 196-206.

Hughes, W. and Shinoda, H. (1999) 'Achieving satisfactory contractual terms for the Engineer's role', In Hughes, W. (ed.), Proceedings of the $15^{\text {th }}$ ARCOM Conference, September 1999, Liverpool, 597-606.

Koksal, T. (2011) 'FIDIC conditions of contract as a model for an international construction contract', Business and Management Review, 1 (2), 32-55.

Koo, M.M., Krass, I. and Aslani, P. (2003) 'Factors influencing consumer use of written drug information', The Annals of Pharmacotherapy, 37, 259-267.

NEC (2005) NEC3 Engineering and Construction Contract (ECC), London.

Orlow, M.K.P., Taylor, H.A. and Brancati, F.L. (2003) 'Readability standards for informedconsent forms as compared with the actual readability', The New England Journal of Medicine, 348, 721-726.

Paz, S.H., Liu, H., Fongwa, M.N., Morales, L.S. and Hays, R.D. (2009) 'Readability estimates for commonly used health-related quality of life surveys', Quality of Life Research, 18, 889-900.

Perry, J.G. (1995) 'The new engineering contract: principles and design of risk allocation', Engineering, Construction and Architectural Management, 2, 197-208.

Pettit, D. (2012) 'The effect of the New Australian Consumer Law on the use of standardform contracts within the Australian construction industry', Journal of Legal Affairs and Dispute Resolution in Engineering and Construction, 4 (1), 1-9.

Raj, S., Hilling, J. and Hughes, W. (2009) 'Responsiveness to change by standard-form contract drafters in the construction industry: A case study of the FIDIC White Book', International Journal of Law in the Built Environment, 1, 205-220.

Rameezdeen R. and Rodrigo, A. (2013) 'Textual complexity of standard conditions used in the construction industry', Australasian Journal of Construction Economics and Building, 13 (1), 1-12.

Rameezdeen, R. and Rajapakse, C. (2007) 'Contract interpretation: the impact of readability', Journal of Construction Management and Economics, 25, 729-737.

Rutherford, B.A. (2003) 'Obfuscation, textual complexity and the role of regulated narrative accounting disclosure in corporate governance', Journal of Management and Governance, 7, 187-210.

Seifert, B.M. (2005) 'International construction dispute adjudication under international federation of consulting engineers conditions of contract and the dispute adjudication board', Journal of Professional Issues in Engineering Education and Practice, 131, 149-157.

Shnookal, T. and Charrett, D. (2010) 'Standard form contracting; the role for FIDIC contracts domestically and internationally', Proceedings of the society of construction law conference Australia, Perth.

Sweet, J. (1989) 'Standard construction contracts: Some advice to construction lawyers', South Carolina Law Review, 40 (4), 823-845.

Swiney, G. (2007) 'The dubious upgrade of international development contracts', International Law \& Management Review, 3, 145-169.

Sydserff, R. and Weetman, P. (2002) 'Developments in content analysis: a transitivity index and DICTION scores', Accounting Auditing and Accountability Journal, 15, 523-545. 
Thomas, H.R., Smith, G.R. and Mellot, R.E. (1994) 'Interpretation of construction contracts', Construction Engineering and Management, 120, 321-336.

Velez, P. and Ashworth, S.D. (2007) 'The impact of item readability on the endorsement of the midpoint response in surveys', Survey Research Methods, 1 (2), 69-74.

Wright, J.N. and Fergusson, W. (2009) 'Benefits of the NEC ECC form of contract: A New Zealand case study', International Journal of Project Management, 27, 243-249. 